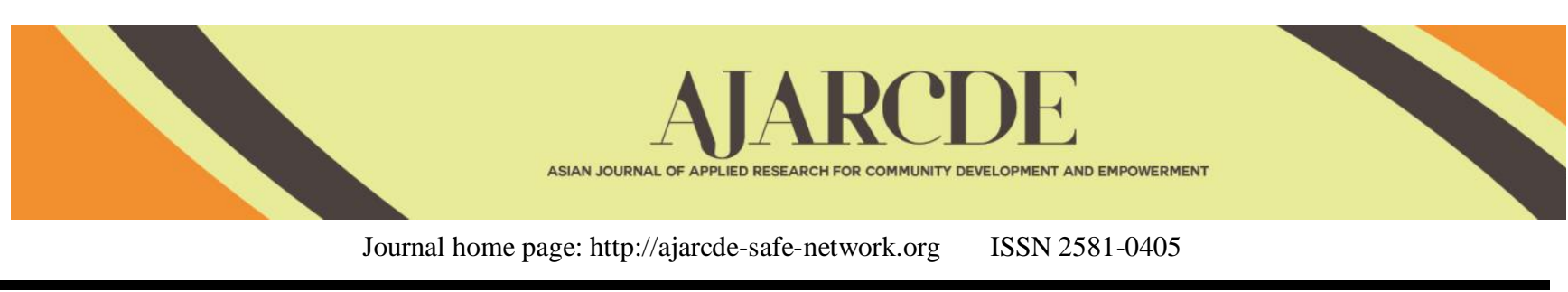

\title{
The Promotion of Beekeeping and Bee Product and By-Product Development at PSAU, Philippines
}

\author{
Norman G. de Jesus*, Estrella C. Zabala, Elena B. Pineda, Regina D. Loria, Emmanuel Pangilinan and \\ Honorio M. Soriano Jr \\ Alternative Low Input Agricultural System, Pampanga State Agricultural University, Magalang, Pampanga. Email: normandejesus2005@yahoo.com.ph
}

\section{ARTICLE INFO}

Article History::

Received: 22 October 2019

Final Revision: 10 January 2020

Accepted: 01 March 2020

Online Publication: 05 March 2020

\section{KEYWORDS}

beekeeping, bee product, bee by-product CORRESPONDING AUTHOR

*E-mail: normandejesus2005@yahoo.com.ph

\section{A B $\quad \mathbf{S}$ T $\mathbf{R}$ A $\mathbf{C}$ T}

\begin{abstract}
The study is divided into two components, namely; the beekeeping status and contribution of bees as pollinators and the development of its by-products. The first component is on documentation of existing beekeeping activity and honey utilization in Region III; Inventory of bee plants surrounding Mt. Arayat and the contribution of the honeybee as pollinators to selected tropical fruit trees and vegetable crops. The second component, which is on the development of products and by-products came up with a honey wine formulation and eight wellness products. The general objective of this project is to promote beekeeping, its products, and by-products developed among various communities in the vicinity of Mt. Arayat and nearby municipalities of Pampanga. Beekeepers are members of the Beekeeper Association, Luzon Chapter. The type of race usually found in the research places is Apis millifera where the number of colonies of the Beekeepers ranges from 4 to 48 . The farm size for beekeeping ranges from 1000 to 5000sq.m. Beekeepers observed proper hive placement, density, water, and management. As to training needs the beekeepers said that they need training on the global trends in beekeeping, a quality race of bees (queen) and packaging technology for honey. Eight forest trees, 12 vegetables, five field crops, 13 fruit trees, six ornamental plants, and four wild plants have so far been identified and were found within PAC surroundings and vicinity of Mount Arayat. These plants varied in their flowering time which makes them good sources of nectar and pollen all year round for the honeybees. There are plants bearing either nectar or pollen, and there are also plants that possess both the nectar and pollen. The study showed that honeybees could affect the fruit size and harvest of cashew, squash, cucumber, and tamarind fruits. The honey wine developed is very much acceptable in terms of appearance, aroma, and taste. The wellness products were very effective in the specific study conducted such as acne, wound healing, and rashes, among others. There were about 500 individuals who were afforded with either of the following technology transfer: hands-on training, seminar, orientation and the likes.
\end{abstract}

\section{INTRODUCTION}

\subsection{Research Background}

With the aim of the state in maximizing the utilization of Beekeeping to augment the livelihood of the society budget was released for the project resulting to the realization of the herein reported activities. Two races of bees have been acquired, namely Apismillerfera which was obtained from DMMMSU-NARTDI, Bacnotan, La Union and Trigonasppor the stingless bees obtained from CBSUA, Pili, Camarines Sur. Majority of the field experiments were already conducted like; "contribution of honeybees as pollinator to fruit and vegetable production. Bee foraging in the immediate environs of Mount Arayat was also evaluated, likewise, beekeeping activities in the region was surveyed. Various food and non-food products were also developed and evaluated for acceptability, safety and efficacy. There were about 500 individuals who were exposed to orientation and hands-on training not only on the importance of beekeeping on crop productivity enhancement, but also on various products that can be developed from honey, honey byproducts, beeswax and propolis as an additional livelihood of the community. Hands-on training were conducted among vegetable raisers, coffee and fruit orchard farmers, educators, students from Masteral degree program, College students who specializes in Biology, Agriculture, Engineering, Developmental Communication, Science Education, Science High School 
students and even to local government officials, NGO'S with their beneficiaries and members benefited on the technology diffusion of this project.

\subsection{Research Objective}

The general objective of this project is to promote beekeeping among various communities in the vicinity of Mt. Arayat and nearby municipalities of Pampanga. The specific objectives are as follows: (1) To upscale the apiary of PAC for training, research and extension purposes; (2) To conduct relevant researches (documentation of indigenous beekeeping practices; pollination; foraging behavior and economics); and (3) To extend beekeeping technologies to farmers through training.

\section{MATERIALS AND METHODS}

\subsection{Up-scaling of the apiary of PSAU}

The apiary, which consists only of 10 colonies of Apis mellifera, was amplified with 15 starter colonies and 15 colonies of stingless bees, Trigona spp. Hives and associated equipment were fabricated and some were purchased. The initial harvest of about $150 \mathrm{~kg}$ honey were made into wine and other food and nonfood products. Beeswax and Propolis are two other by product of this Beekeeping Project. Beeswax was used greatly in the production of skin treating products as well as in preparing mosquito repellent candles. Propolis on the other hand was utilized in analysis for its possible health benefits. Although typhoon "Santi" caused devastation in the project that destroyed 15 colonies of Apis millefera and 10 colonies of Trigona spp, Beeswax and propolis were still recovered and were used in the conduct of relevant researches and product development. With the funding assistance for the project, additional bee colonies were purchased and splitting were undertaken to further boost its production capacity.

\subsection{Documentation of beekeeping practices and indigenous knowledge and bee product utilization}

The Beekeepers of Region III are located in Gabaldon, Nueva Ecija, Abucay, Bataan and Bulacan. Beekeeping farmers are members of Beekeeper Association, Luzon Chapter. The type of race usually found in the research places is Apis millifera where the number of colonies of the Beekeepers ranges from 4 48 colonies. The farm size for beekeeping ranges from 1000sq.m to 5000sq.m. Beekeepers observed proper hive placement, density, water and management. The practices of the three provinces are comparable to the operation and management of an ideal bee farm where four critical requirements are considered, given the needs of bees for beeswax, nectar, water and other sources of pollen (Natural Resource Management Program 2UPBC,2001). The comparable practices of the beekeepers in the region may be attributed to their membership in Beekeepers Association wherein they are motivated to adapt the practices set by the Association. The main products of the beekeepers include honey, bee pollen, beeswax and bee venom. Their training needs includeprovision of training on the global trends in beekeeping, quality race of bees (queen) and packaging technology

\subsection{Inventory of Bee Plants Surrounding Mount Arayat in Pampanga}

Eight forest trees, 12 vegetables, five field crops, 13 fruit trees, six ornamental plants and the four wild plants have so far been identified and were found within PAC surroundings and vicinity of Mount Arayat. These plants varied in their flowering time, which make them good sources of nectar and pollen all year round for the bees. There are plants bearing either nectar or pollen, and there are also plants which possess both nectar and pollen. The honeybees like to forage on narra, acacia, palm trees and flowering ornamentals and fruit trees. Host plants for bees surrounding Mount Arayat are almost the same host plants for bees in the Cordillera (Natural Resource Management Program 2 - UPBC,2001). Their foraging habit usually lastsfrom 6:00 to 9:00 A.M. and 4:00 to 6:00 P.M.

There are common trees found in Mount Arayat include Narra, Mahogany, Acacia, Kakawate, Banaba, Molave, Eucalyptus and Ipil-ipil. These trees were the visited by the bees but the most frequently visited were Acacia and Banaba. These trees were preferred because bees need pollen and nectar for their reproduction and growth, which these tree species provide.

\subsection{Contribution of Honeybees as Pollinators to Selected Tropical Fruit Trees and Organic Vegetable Crops}

Cucumber, corn, pechay, mustard, patola, horse radish, squash and bitter gourd were visited by the bees at different months of the year but the frequently visited vegetables were cucumber, patola and corn. The table indicates that bees visited most of the vegetables for their pollen and nectar. Estimation of gas production and energy analysis

\section{RESULT AND DISCUSSION}

\subsection{Inventory of Honeybees Presence on Selected Vegetables and Field Crops at Different Month of the Year}

Data shows that both trees and vegetables were visited by bees at different months of the year. Sitao, Kadyus, Peanut, Duhat and Camachile were visited for their pollen and nectar while Tomato, Rice, Sweet Sorghum, Sweet Potato, Guava and Mabolo were visited because of their nectar. The table indicates that the frequently visited vegetables were Pole and Bush Sitao, Tomato, and Peanut while Duhat and Camachile were frequently visited compared with Guava and Mabolo.

\subsection{Contribution of Honeybees to Productivity of Cherry Tomatoes}

Significant differences on the number of fruits, length of fruits and width of fruits of Cherry Tomatoes raised at different conditions. Treatment 1 and Treatment 3 shows no significant difference on the size of the Cherry Tomato fruit. While Treatment 2 showed significant difference with Treatment 1 and 3. This indicates that honeybees could affect the fruit size of Cherry Tomatoes 
Table 1. Contribution of Honeybees to productivity of cherry tomatoes

\begin{tabular}{|l|l|l|l|}
\hline TREATMENT & $\begin{array}{l}\text { No. OF } \\
\text { FRUITS } \\
\text { PER PLANT }\end{array}$ & $\begin{array}{l}\text { LENGTH OF } \\
\text { FRUITS } \\
(\mathrm{cm})\end{array}$ & $\begin{array}{l}\text { WIDTH OF } \\
\text { FRUITS } \\
(\mathrm{cm})\end{array}$ \\
\hline $\begin{array}{l}\text { Treatment 1 - } \\
\text { With net, no bees }\end{array}$ & $71.33^{\mathrm{b}}$ & $1.33^{\mathrm{b}}$ & $0.42^{\mathrm{c}}$ \\
\hline $\begin{array}{l}\text { Treatment } 2- \\
\text { With net and bees }\end{array}$ & $139.66^{\mathrm{a}}$ & $1.77^{\mathrm{a}}$ & $0.90^{\mathrm{a}}$ \\
\hline $\begin{array}{l}\text { Treatment } 3- \\
\text { Open field, no } \\
\text { bees }\end{array}$ & $92.66^{\mathrm{b}}$ & $1.59^{\mathrm{b}}$ & $0.59^{\mathrm{b}}$ \\
\hline
\end{tabular}

\subsection{Contribution of Honeybees to Productivity of 3- Year Old Sweet Tamarind Trees at PSAU-ALIAS}

Results show significant differences on the number of Sweet Tamarind fruit which were produced at different conditions. Treatment 2, Tamarind with net and with Honeybees obtained the highest mean. This is followed by Treatment 3 which is Tamarind in Open field. Treatment 1 which was Tamarind with net and with no Bees had the lowest mean. This indicates that the presence of Honey bees could increase the Sweet Tamarind fruit production.

Table 2. Contribution of Honeybees to productivity of sweet tamarind.

\begin{tabular}{|l|c|c|c|c|}
\hline TREATMENT & \multicolumn{4}{|l|}{$\begin{array}{l}\text { MEANS ON TAMARIND FRUIT } \\
\text { PRODUCTION }\end{array}$} \\
\hline $\begin{array}{l}\text { Treatment 1 - With } \\
\text { net, no bees }\end{array}$ & $165.50^{\mathrm{b}}$ & $18.66^{\mathrm{c}}$ & $1.10^{\mathrm{c}}$ & $25^{\mathrm{c}}$ \\
\hline $\begin{array}{l}\text { Treatment 2-With net } \\
\text { and bees }\end{array}$ & $250.00^{\mathrm{a}}$ & $46.66^{\mathrm{a}}$ & $1.73^{\mathrm{a}}$ & $67^{\mathrm{a}}$ \\
\hline $\begin{array}{l}\text { Treatment 3 - Open } \\
\text { field, no bees }\end{array}$ & $197.66^{\mathrm{c}}$ & $35.00^{\mathrm{b}}$ & $1.27^{\mathrm{b}}$ & $56^{\mathrm{b}}$ \\
\hline
\end{tabular}

\subsection{Non-food Products Developed Using Honey and Honey By-Products}

Honey is an ancient remedy for the treatment of infected wounds, which has recently been 'rediscovered' by the medical profession, particularly where conventional modern therapeutic agents are failing. There are now many published reports describing the effectiveness of honey in rapidly clearing infection from wounds, with no adverse effects to slow the healing process; there is also some evidence to suggest that honey may actively promote healing. In laboratory studies, it has been shown to have an antimicrobial action against a broad spectrum of bacteria and fungi [1]. Beeswax refers to the natural wax produced by honeybees in their beehives. The honeybees produce this wax either to build their honeycombs or to repair it. Since ancient times, the basic recipe for creams and ointments has consisted of a mixture of beeswax and oil in various proportions according to the desired consistency. Beeswax has an irritation potential of zero, and a comedo genicity rating of $0-2$, which means that when formulated and used correctly in cosmetic formulations, beeswax will not cause a problem, but brings a host of very positive attributes, such as general healing and softening, as an antiseptic, and an emollient to cosmetic products [2].
Generally, the researcher aimed to find out the efficacy and acceptability of the non-food products developed from honey and honey by-products.

\subsubsection{Identify the anti-inflammatory, anti-fungal, wound healing, anti-bacterial properties and effects on some skin diseases of honey soaps developed;}

\subsubsection{Describe the acceptability of (a)honey lip} balm; (b) lotus-honey body scrub; (c) tamarind shower gel with honey; and (d) beeswax candle with citronella extract.

Experimental and descriptive methods were the research design used in the gathering of information to attain the objectives of the study. Rabbits and mice were the laboratory animals used in the study. Rules on the ethical used of laboratory animals were strictly followed and properly guided by a licensed veterinarian. Oral and written testimonies of human respondents were also recorded accordingly. A survey questionnaire was floated among identified respondents. Only respondents of legal age were included. The formulation of procedure in the making of the nonfood products: soap, lip balm, body scrub, shower gel and candle followed the standards set by Food and Drugs Cosmetics Act of the Philippines. The non-food products developed using honey and honey-by products were the following:

\section{A. Honey moisturizing soap}

Honey has used in personal care products because of its skin conditioning effect. Additional to using honey's antibacterial activity, advantage is being taken of its other medically beneficial bioactivities: a rapid debriding action, a stimulatory effect on growth of tissues for wound repair, an anti-oxidant activity and an anti-inflammatory action, which minimises scarring. With this majestic property of Honey, the researcher of this study sought to prove the skin benefits of Honey in the form of a soap.

\section{B. Lotus enriched with honey soap}

The pre-formulation stage of this study includes the development of germicidal lotus soap particularly used as an anti -acne and wound healing soap. The soap contains Lotus Leaves extract and Honey. According to Ref. [3] that Nelumbo nucifera possess to have flavonoids, alkaloids and tannins. These bio-actives of Lotus are known to reduce inflammation and oxidative stress, promote healing and repair skin damage. The white flower extract of Lotus is known to have antibacterial and antioxidant effect. These makes it possible for Lotus soap to works wonders on skin with inflammations such as on acne and wounds. Honey was added to the development of Lotus soap to further enhance the quality of the product. The objective of this lotus soapis to promote a soap composition, with natural antibacterial effect of the lotus leaves extract against acne. The soap is used to cleanse away dirt and remove pimple causing bacteria. Another feature of this soap is for washing cuts and wounds which can support the healing of the skin because of its natural antibacterial, antiinflammatory and antioxidant agents. To test the wound healing effect of Honey Lotus Soap, The respondents were given one week to use and observe the effect of the soap on their wounds. The respondents were instructed to use the soap twice a day to 
prevent irritation. They were instructed to evaluate the effect of the soap such as the skin color and lesions.

\section{Tamarind Soap with Honey}

The soap was tested for its antibacterial effect, specifically against Staphylococcus aureus. The soap has an average of $2.00 \mathrm{~mm}$ zone of inhibition; hence the soap has potential antibacterial property. The soap was enriched with Honey to further enhance the quality of the soap. The soap was used and tested by 20 respondents with acne and it was described to be effective in decreasing the number of acne, decreases the size of the acne, lightens the color of scars from pimples and lightens the color of the skin.

\section{Lotus (Nelumbo nucifera)-beeswax ointment}

The effects of the lotus-beeswax ointment were comparable to the commercial cream, Indomethacin Vi-gel. The reduction of inflammation on the rabbits' hind paws were significant on the first and fourth hour and is highly significant on the second and third hour while the fifth, sixth and seventh hour showed no significance in terms of time intervals.

\section{E. Tamarind Beeswax Ointment}

The prepared ointments are effective and are comparable with the positive controls in reducing the inflammation on the inflamed hind paws of rabbits. Sweet tamarind showed rapid reduction of inflammation because of the phytochemicals it contains such as alkaloids, flavonoids and flavonols, which are known to reduce inflammation and oxidative stress, promote healing and repair skin damage [4]. Alkaloids also occur in the leaves, pulp and bark of pure extract function as photoprolectants, modulate antibacterial effects and reduction of inflammation [5]. Beeswax has an irritation potential of zero, and a comedo genicity rating of $0-2$, which means that when formulated and used correctly in cosmetic formulations, beeswax will not cause a problem, but brings a host of very positive attributes, such as general healing and softening as an antiseptic, and an emollient to cosmetic products [2].

\section{E. Adlai Beeswax Ointment}

Literature indicates that Adlai leaves possess skin healing effect because they contain phytochemicals. Beeswax was used in the preparation of the ointment because it brings a host of very positive attributes, such as general healing and softening, as an antiseptic, and an emollient to cosmetic products [2].

\section{F. Honey Lip Balm}

The pre-formulation stage of this study included the development of soothing Lotus - Honey Lip Balm particularly used as lip moisturizer and for wound healing. Lotus contains moisturizing and antioxidants substances that are essential to keep the lips healthy. The Lip Balm is enriched with Honey to further hasten its moisturizing and wound healing effect. The pre-formulation stage of this study included the development of soothing Honey Lip Balm particularly used as lip moisturizer and for wound healing. Honey contains moisturizing substances that are essential to keep the lips healthy.

\section{G. Rejuvenating and Skin Nourishing Lotus-Honey Body Scrub}

4 de Jesus et al.
This rejuvenating and skin nourishing Lotus - Honey body scrub naturally exfoliates dead skin thus it allows skin to absorb skin nutrients that comes from Lotus and Honey Lotus and Honey contains antioxidants that prevent skin aging. Hence, this product was formulated to combine the health benefits of Lotus and Honey. Estimated price per 100g is P 100.00 .

\section{H. Tamarind Shower Gel with Honey}

Result of this study showed the comparative acceptability of the Tamarind Shower Gel with Honey and the Commercial Shower gel in terms of their color, odor, texture, viscosity, appearance and effectiveness. Results of this study indicate that Tamarind shower gel with Honey possess antibacterial potential against Staphylococcus aureus. Citronella has established literature for its muscle relaxing effect as well as insect repellent effect. With this, the researcher developed beeswax candle with citronella extract to prove further the uses of beeswax not only for cosmetics but also for energy use. Based on the data gathered from the study, it can be concluded that the non-food products made from honey and honey-by-products are effective and their efficacy as intended are manifested as shown by test with laboratory animals and testimonies of human respondents. Testing and introducing the non-food products made from honey and honey-by-products in a wider community is hereby recommended. Also, the researcher recommends exploring the use of food additives in lieu of other chemicals in making the non-food products.

\subsection{Food Products Developed Using Honey}

Honey wine or Mead is an alcoholic beverage that is produced by fermenting a solution of honey, water, sugar and yeast. Honey wine is also called: Drinkable Honey, Wedding Wine, or Drink of Love. Honey Wine has a good level of antioxidants from honey. Honey wine contains no gluten and therefore can be enjoyed by people with celiac disease or wheat sensitiveness.

Objectives of the Study. The general objective of the study is to describe PAC honey and utilize it in making wine. Specifically, the study aimed to describe the PAC honey wine produced in terms of organoleptic properties of appearance, bouquet, taste, and over all acceptability. To be able to describe PAC honey laboratory analysis were done. Other samples of honey from other places were likewise analyzed. Laboratory analysis was done by DOST-3. PAC Honey wine was made by determining the amount of water and sugar to add in honey to produce honey wine that conforms to the PNS (Philippine National Standards) for tropical wine.

\subsection{Training and Extension Activities}

There were about 500 individuals who were given orientation and hands-on training about various products that can be developed from honey as well as on basic beekeeping practices. Hands-on activities were conducted among coffee and fruit orchard owners/farmers, organic agriculture enthusiasts, NGOs, local government units, educators, students from different programs and from different schools have been received asking about the contribution of honeybees to enhance the fruit set. Worth noting is the video production of Cynthia Tizon of Going Green, an agri-TV show aired at PEP TV Channel-11. Said video showcases the various products developed from Beeswax and Honey. Another video was taken by CLTV-36, a local TV station, covering highlights on bee management and product development. 


\section{CONCLUSION}

The 15 starter colonies and 15 colonies of stingless bees, Trigona spp. Hives harvest of about $150 \mathrm{~kg}$ honeys were made into wine and other food and non-food products.. The type of race usually found in the research places is Apis millifera where the number of colonies of the Beekeepers ranges from $4-48$ colonies. The farm size for beekeeping ranges from 1000sq.m to 5000sq.m.Beekeepers observed proper hive placement, density, water and management. The host plants of Mount Arayat includes on narra, acacia, palm trees and flowering ornamentals and fruit trees which either bear nectar or pollen. Where Acacia and Banaba are the frequently visited trees. The foraging habit of bees usually lasts from 6:00 to 9:00 A.M. and 4:00 to 6:00 P.M.The bees visited vegetable crops at different months of the year, however the frequently visited vegetables includes cucumber, patola, corn, pole and bush sitao, tomato, and peanut. The $\%$ fruit set of Cashew is $68 \%$, Tamarind is $42 \%$, Squash is $61 \%$ and Cucumber is $45 \%$ respectively. The exposure of cherry tomatoes to native bees improved fruit size both in length and diameter, fruit weight, plant height for 30,60 , and 90 days after seeding, color, number of marketable fruits per treatment, number of non-marketable fruits per treatment and average number of fruits per treatment. Honey was added to the development of Soap (Honey, Lotus- honey, Tamarind - Honey), Shower Gel, Body Scrub to further enhance the quality of the products. Where Honey was used as an emulsifying agent, skin conditioner and antibacterial agent. Beeswax wax used in the production of ointments, creams and lip balm because of its emollient effect and general healing effect. Honey can use as a raw material in the production of Wine and as a Glaze for Adlai bread. Beekeeping technology benefited different group of individuals in the community which includes Upland and Lowland Farmers, Women, Professionals and Students.

\section{REFERENCE}

[1] Molan P. 2009. "Honey: antimicrobial actions and role in disease management," in New Strategies Combating Bacterial Infection, I. Ahmad and F. Aqil, Eds., pp. 229 253, Wiley-VCH Verlag GmbH \& Co. KGaA, Weinheim, Germany

[2] Bogdanov S. (2009): Beeswas : Uses and Trade.The Book of Honey. Bee Product Science. Retrieved September 2013 from www.bee-hexagon.net p 13- 15

[3] Dhanarasu S and Awdah Al-Hazimi. 2013. . Phytochemistry, Pharmacological And Therapeutic Applications Of Nelumbo Nucifera. Asian Journal of Phytomedicine and Clinical Research. 1 (2), 2013, 123 136.

[4] Mohamad M Y, H B Akram, D N Bero and M T Rahman. 2012. Tamarind Seed Extract Enhances Epidermal Wound Healing. International Journal of Biology, Vol. 4, No. 1: 81-88

[5] Pineda, A.J., Pongos,P.B. Loria, R. D. 2014. AntiInflammatory Potential of Lotus (Nelumbonucifera)Beeswax Ointment in Rabbits (Oryctalaguscuniculus) Pampanga Agricultural College, Magalang, Pampanga $\mathrm{p}$ 29-38 